\title{
Is the basic life-cycle theory of consumption becoming more relevant? Evidence from Portugal
}

\author{
Fernando Alexandre*, Pedro Bação ${ }^{\dagger}$ and Miguel Portela ${ }^{\ddagger}$
}

October 25, 2019

doi: https://doi.org/10.1007/s11150-019-09471-0

(C)2019. This manuscript version is made available under the CC-BY-NC-ND 4.0 license http://creativecommons.org/licenses/bync-nd $/ 4.0 /$

This research is financed by National Funds of the FCT - Portuguese Foundation for Science and Technology within the project UID/ECO/03182/2019.

This paper benefited greatly from the comments of the Editor, the CoEditor and two anonymous referees.

This is a post-peer-review, pre-copyedit version of an article published in [Review of Economics of the Household]. The final authenticated version is available online at: http://dx.doi.org/

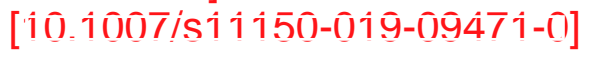

*NIPE/Universidade do Minho. Address: Universidade do Minho, Escola de Economia e Gestão, Campus de Gualtar, 4710-057 Braga, Portugal. Orcid: 0000-0001-7933-7885.

${ }^{\dagger} \mathrm{CeBER} / \mathrm{GEMF} /$ Universidade de Coimbra. Address: Faculdade de Economia da Universidade de Coimbra, Av.Dias da Silva 165, 3004-512 Coimbra, Portugal. Orcid: 0000-0002-3340-1068. Corresponding author. E-mail: pmab@fe.uc.pt. Telephone: +351 239790500 .

$\ddagger$ NIPE/Universidade do Minho and IZA Bonn. Address: Universidade do Minho, Escola de Economia e Gestão, Campus de Gualtar, 4710-057 Braga, Portugal. Orcid: 00000002-4721-2081. 


\begin{abstract}
In this paper we report and discuss estimates of life-cycle consumption profiles obtained using microdata for Portuguese households. The estimated profiles are much flatter than the profiles usually reported in the literature for other countries, namely the Netherlands, the UK and the USA. In addition, we also report estimates of cohort and business cycle effects on consumption. The estimated cohort effects are consistent with the post-war progress in median standards of living. However, there is a deceleration in the trend of consumption growth for more recent cohorts. The business cycle estimates suggest that the recent debt crisis has had a strong negative impact on household consumption.
\end{abstract}

Keywords: cohorts, consumption, life-cyle, microdata JEL classification: D15, E21 


\section{Introduction}

To the best of our knowledge, this is the first paper to report estimates of a life-cycle consumption profile for Portuguese households allowing for time and cohort effects. We find a much flatter life-cycle consumption profile than the profiles reported in the literature for other countries - see, e.g., Alessie and Ree (2009) for the Netherlands, Banks et al. (2016) for the UK, and Gourinchas and Parker (2002), Aguiar and Hurst (2013) and FernándezVillaverde and Krueger (2007) for the USA.

In the present paper we focus exclusively on estimating a life-cycle consumption profile, in the vein of Fernández-Villaverde and Krueger (2007). In this context, consumption is modelled as the result of three effects: age, time and cohort. Age effects correspond to the life cycle: how consumption varies as individuals grow older. Time effects correspond to the "business cycle": the economic conditions prevailing in each year may induce more or less consumption relative to average consumption. While time effects are temporary, cohort effects represent permanent effects on average lifetime consumption related to the period during which an individual is active. For example, individuals that entered the labour market in 1980 faced a very different environment than individuals that entered the labour market in 2000, with consequences for lifetime consumption. The estimation of cohort effects attempts to quantify such differences.

It must be noted that, during the twentieth century, Portugal went through a process of growth and structural transformation. The main transformations occurred in the final quarter of the twentieth century, decades after the more advanced European countries. The drivers of that transformation were democracy and the accession to the European Union. The creation of a universal welfare state in Portugal took place after the democratic regime was installed. The development of financial markets accelerated during the 1980s, and greatly benefited from the participation in the Economic and Monetary Union (EMU). Expenditure on education and health increased substantially. One of the most visible consequences of this evolution was the increase in life expectancy - according to data from PORDATA ${ }^{1}$, life expectancy for women rose from 66.4 years in 1960 to 83.4 years in 2016. All these factors are relevant for consumption choices over the life cycle and make Portugal an interesting subject of research.

The behaviour of consumption has been one of the most controversial issues in the debate about the causes and consequences of the dismal performance of the Portuguese economy in the twenty-first century. The drop

\footnotetext{
${ }^{1}$ https://www.pordata.pt/
} 
in the level of aggregate savings is a proximate cause of the external imbalances that led to the bailout of 2011 - see, e.g., Reis (2013), Baldwin et al. (2015) and Alexandre et al. (2017) - as it had been of the previous two interventions of the IMF in Portugal (in 1977 and in 1983/84). Understanding consumption behaviour is therefore an important issue for the Portuguese economy.

Previously reported life-cycle profiles of consumption in Portugal have been based on a cross-section of household data - see Alves and Cardoso (2010) and Banco de Portugal (2018). The use of just a cross-section to estimate the life-cycle profile of expenditure makes the time effects irrelevant, but confounds the life-cycle and cohort effects. The procedure we use to separate the three effects follows Fernández-Villaverde and Krueger (2007), which is based on the framework developed by Deaton and co-authors - see Deaton (1997) and the references therein. To that end, we use microdata extracted from household budget surveys to construct a pseudopanel that follows cohorts over time. The pseudopanel includes a measure of consumption (the median consumption of the cohort in each year), besides cohort (defined by the year of birth of the reference person) and time (year of the survey) dummies - details are provided in section 3. Other studies that employ a similar procedure are Zhou (2012) for China, Jappelli (1999) for Italy, Alessie and Ree (2009) for the Netherlands, Banks et al. (1998) for the UK, Attanasio and Weber (1995), Attanasio (1998), Gourinchas and Parker (2002), Aguiar and Hurst (2013), and Lim and Zeng (2016) for the USA, and Banks et al. (2016) for both the UK and the USA.

Our study also contributes to the issue of the empirical adequacy of the life-cycle/permanent income consumption theory - see the surveys in Browning and Crossley (2001) and Attanasio and Weber (2010). This theory predicts that the consumer will try to smooth consumption over the life cycle. In the simplest models, the slope of the (linear) consumption profile will depend on the comparison between the interest rate and the rate of discount (time preference). As discussed in the surveys mentioned above, there are other versions of the model that consider issues such as end-of-life uncertainty, bequests and liquidity constraints. These versions may produce a humpshaped consumption profile, as found, for example, in Fernández-Villaverde and Krueger (2007) and Gourinchas and Parker (2002).

In line with previous results based on cross-sectional data (Alves and Cardoso 2010; Banco de Portugal 2018), our estimated consumption profiles for the Portuguese households appear to be much flatter than the usual estimates. In this sense, our results are closer to what the life-cycle theory of consumption predicts. However, consumption of older households, namely those over sixty years old, tends to decrease, as has been reported in the 
literature - see, e.g., Banks et al. (1998) and Banks et al. (2016).

The paper is organized as follows. In section 2 we describe the data from the Household Expenditure and Budget Surveys for Portugal. In section 3, we describe the methodology to identify the life cycle, the cohort and the business cycle effects. In section 4, we present the estimates of the lifecycle consumption profile, as well as of cohort and business cycle effects on households' consumption. Section 5 concludes and suggests some hypotheses that may be investigated by future research on the flatter life-cycle profile found for Portuguese households.

\section{Description of the IDEF survey data}

In our analysis we use data from the survey "Inquérito às Despesas das Famílias (IDEF)" (Household Budget Survey) made available by Statistics Portugal (INE). This survey is used by INE to determine the consumption basket underpinning the Consumer Price Index - for more details see INE (2017). Given the changes that the survey has undergone, we will use only the four most recent releases, namely 2000/2001, 2005/2006, 2010/2011 and $2015 / 2016$, with a total of 33,932 observations.

Each survey is carried out between March of the first year and March of the following year. In this paper we will often use the first year to identify each survey (e.g. 2000 for the 2000/2001 survey). The IDEF survey comprises four modules, described in INE (2017, p. 92). Module I attempts to characterize the accommodation, the household and the household members. Module II collects data on daily consumption of the household, while module III collects data on daily consumption of the individual members. Module IV gathers retrospective information on consumption expenditures that occurred during the previous year. The data on annual consumption provided by IDEF (segmented according to the United Nations Statistics Division Classification of Individual Consumption by Purpose - COICOP), together with the data on the characteristics of the accommodation, of the household and of its members that INE has made available (which is not the full set of data collected), forms the essential of our dataset.

From the original series provided by IDEF we computed the consumption aggregates on which we will focus our analysis: total expenditure, expenditure on durables, expenditure on nondurables and expenditure on healthdetails are provided in Appendix A. Total expenditure equals the sum of expenditure on durables, expenditure on nondurables, expenditure on health, and also expenditure on clothing and footwear and on education. Given that the last two components (clothing and footwear, and education) are very 
small (often zero) for most of the households, the disaggregate analysis will not be carried out for these two components. Tables 3 and 4 present descriptive statistics for total expenditure and these components. The values have been converted to thousands of 2015 euros, using the Consumer Price Index for each component, which implies that the sum of the components does not equal total expenditure. Average total expenditure is around 20 thousand euros, varying between a minimum of 100 euros and a maximum of 229 thousand euros. The very low minimum total expenditure suggests that observations at the lower end may be subject to considerable measurement error. Naturally, the same may be true for the components of total expenditure. In several cases, the minimum is zero. The frequency of zero expenditure is particularly important in the case of health (25\% of observations), clothing and footwear (20\%), and, specially, education expenditures $(80 \%)$. It should be noted that education expenditure in IDEF only includes fees. For example, books are part of recreation and culture expenditures, while school transportation is part of transport services. This differs from the classification of household expenditures in the Consumer Expenditure Survey (CEX) used by, e.g., Fernández-Villaverde and Krueger (2007) - see Appendix A.

The population considered in the survey includes all households that in each period live in Portugal. Individuals living in collective accommodation are excluded. The households actually surveyed were assigned a weight by INE; in our empirical analysis we use that weight to compute the aggregates of consumption for each cohort. Specifically, we will compute the weighted median of each expenditure aggregate (total expenditure, durables, etc.) for each cohort in each survey. Furthermore, we will also use an "adult equivalent" measure of expenditure to take into account the size and composition of the household - see the evolution of the average size of the household by age of the reference person in Table 1 . The IDEF provides the OECD adult equivalent size of each household. Nevertheless, we follow FernándezVillaverde and Krueger (2007) and compute adult equivalent consumption by dividing household expenditure by the mean of a set of adult equivalence measures which includes the OECD scale - see Fernández-Villaverde and Krueger (2007), namely footnote 6, for details.

The original dataset contained a few households with a reference person under the age of 25. Given their small number, these observations were dropped. We also deleted from the sample households for which information was missing regarding the occupation and/or the gender of the reference person of the household. The distribution of the observations in each survey per age category of the household's reference person is presented in Table 2. However, we only have information concerning the exact age (rather than the 
Table 1: Average size of the household by age of the reference person

\begin{tabular}{lc}
\hline \hline Categories & Average size \\
\hline$[25-29]$ & 3.1 \\
{$[30-44]$} & 3.4 \\
{$[45-64]$} & 2.9 \\
{$[65-74]$} & 2.0 \\
\hline \hline
\end{tabular}

age bracket) of the household's reference person for the 2010 survey and only for reference persons under 75 years old. To overcome the problem we use the information in the 2010 survey to impute ages to the households' reference individual in the other surveys. Obviously, that is not feasible for those households whose reference individual is over age 74 - these were therefore removed from the sample.

The imputation of the age of the household's reference person is done by means of a multinomial logit model, given the known age bracket of the individual. The estimation of the model - using the data of the 2010 surveythen allows us to compute probabilities for each age inside that age bracket, given the characteristics of the household (i.e., using the values taken for each household in the 2000, the 2005 or the 2015 survey, by the explanatory variables of the multinomial logit model). We take as the age of the household's reference person the age with the highest estimated probability. A bootstrap simulation, in which the age of each reference person was randomly drawn from the estimated probability distribution, suggested that the results are robust with respect to that choice - see Appendix B.

The IDEF surveys do not provide a panel dataset, but a set of crosssections. Individuals interviewed in a cross-section belong to different cohorts. Therefore, averaging cross-section data by age may not provide an adequate estimate of the life-cycle consumption profile, because the cohort effects vary across individuals of different ages. In the next section we describe the methodology employed to move from this data to the estimation of life-cycle consumption profiles. 
Table 2: Households' reference person, age groups

\begin{tabular}{lccccc}
\hline \hline Categories & 2000 & 2005 & 2010 & 2015 & Total \\
\hline$[25-29]$ & 229 & 483 & 388 & 306 & 1,406 \\
{$[30-44]$} & 2,096 & 2,775 & 2,158 & 2,743 & 9,772 \\
{$[45-64]$} & 3,735 & 3,669 & 3,494 & 4,303 & 15,201 \\
{$[65-74]$} & 2,220 & 1,791 & 1,628 & 1,914 & 7,553 \\
Total & 8,280 & 8,718 & 7,668 & 9,266 & 33,932 \\
\hline \hline
\end{tabular}

Notes: Number of observations per category in each survey after deleting missing values - see details in the main text. 
Table 3: Descriptive statistics

\begin{tabular}{|c|c|c|c|c|c|}
\hline & 2000 & 2005 & 2010 & 2015 & All \\
\hline \multicolumn{6}{|l|}{ Total expenditure } \\
\hline mean & 17.9 & 20.3 & 21.5 & 20.5 & 20.1 \\
\hline minimum & 0.3 & 0.1 & 0.6 & 1.1 & 0.1 \\
\hline maximum & 164.3 & 229.2 & 143.9 & 191.6 & 229.2 \\
\hline st.deviation & 14.8 & 14.7 & 14.5 & 13.1 & 14.3 \\
\hline $25 \%$ percentile & 8.0 & 10.8 & 11.8 & 12.2 & 10.7 \\
\hline median & 13.8 & 16.7 & 17.7 & 17.3 & 16.5 \\
\hline $75 \%$ percentile & 22.8 & 25.5 & 27.0 & 25.3 & 25.2 \\
\hline zeros $(\%)$ & 0.0 & 0.0 & 0.0 & 0.0 & 0.0 \\
\hline \multicolumn{6}{|l|}{ Nondurable expenditure } \\
\hline $\begin{array}{l}\text { mean } \\
\text { minimum }\end{array}$ & $\begin{array}{l}9.4 \\
0.3\end{array}$ & $\begin{array}{c}11.0 \\
0.1\end{array}$ & $\begin{array}{c}12.1 \\
0.4\end{array}$ & $\begin{array}{c}11.3 \\
0.4\end{array}$ & $\begin{array}{c}10.9 \\
0.1\end{array}$ \\
\hline maximum & 79.8 & 80.0 & 82.4 & 136.9 & 136.9 \\
\hline st.deviation & 7.0 & 7.6 & 8.3 & 7.3 & 7.6 \\
\hline $25 \%$ percentile & 4.6 & 5.7 & 6.2 & 6.4 & 5.7 \\
\hline median & 7.8 & 9.2 & 10.1 & 9.7 & 9.2 \\
\hline $75 \%$ percentile & 12.3 & 14.1 & 15.8 & 14.2 & 14.1 \\
\hline zeros $(\%)$ & 0.0 & 0.0 & 0.0 & 0.0 & 0.0 \\
\hline \multicolumn{6}{|l|}{ Durable expenditure } \\
\hline mean & 6.2 & 7.0 & 7.0 & 6.9 & 6.8 \\
\hline minimum & 0.0 & 0.0 & 0.0 & 0.0 & 0.0 \\
\hline maximum & 119.4 & 94.5 & 97.3 & 92.9 & 119.4 \\
\hline st.deviation & 8.5 & 7.3 & 6.6 & 5.8 & 7.1 \\
\hline $25 \%$ percentile & 1.5 & 3.1 & 3.7 & 3.8 & 3.0 \\
\hline median & 3.5 & 5.2 & 5.4 & 5.5 & 5.1 \\
\hline $75 \%$ percentile & 6.9 & 8.2 & 7.8 & 8.0 & 7.8 \\
\hline zeros $(\%)$ & 0.1 & 0.2 & 0.0 & 0.0 & 0.1 \\
\hline Number of observations & 8,280 & 8,718 & 7,668 & 9,266 & 33,932 \\
\hline
\end{tabular}


Table 4: Descriptive statistics (continued)

\begin{tabular}{|c|c|c|c|c|c|}
\hline & 2000 & 2005 & 2010 & 2015 & All \\
\hline \multicolumn{6}{|l|}{ Health expenditure } \\
\hline mean & 0.9 & 1.2 & 1.3 & 1.2 & 1.1 \\
\hline minimum & 0.0 & 0.0 & 0.0 & 0.0 & 0.0 \\
\hline maximum & 39.2 & 67.4 & 40.3 & 19.9 & 67.4 \\
\hline st.deviation & 1.6 & 2.1 & 2.1 & 1.3 & 1.8 \\
\hline $25 \%$ percentile & 0.0 & 0.0 & 0.0 & 0.3 & 0.0 \\
\hline median & 0.3 & 0.5 & 0.6 & 0.8 & 0.6 \\
\hline $75 \%$ percentile & 1.2 & 1.7 & 1.7 & 1.6 & 1.5 \\
\hline zeros $(\%)$ & 36.8 & 30.6 & 24.3 & 10.6 & 25.2 \\
\hline \multicolumn{6}{|l|}{ Clothing and footwear expenditure } \\
\hline mean & 0.8 & 0.6 & 0.6 & 0.7 & 0.7 \\
\hline minimum & 0.0 & 0.0 & 0.0 & 0.0 & 0.0 \\
\hline maximum & 12.9 & 18.5 & 11.7 & 23.5 & 23.5 \\
\hline st.deviation & 1.1 & 0.9 & 0.9 & 1.1 & 1.0 \\
\hline $25 \%$ percentile & 0.0 & 0.1 & 0.1 & 0.1 & 0.1 \\
\hline median & 0.4 & 0.3 & 0.3 & 0.4 & 0.3 \\
\hline $75 \%$ percentile & 1.0 & 0.8 & 0.8 & 0.9 & 0.9 \\
\hline zeros $(\%)$ & 22.9 & 19.8 & 19.9 & 17.5 & 19.9 \\
\hline \multicolumn{6}{|l|}{ Education expenditure } \\
\hline mean & 0.2 & 0.3 & 0.4 & 0.5 & 0.3 \\
\hline minimum & 0.0 & 0.0 & 0.0 & 0.0 & 0.0 \\
\hline maximum & 28.6 & 46.1 & 15.6 & 32.9 & 46.1 \\
\hline st.deviation & 1.2 & 1.4 & 1.3 & 1.5 & 1.3 \\
\hline $25 \%$ percentile & 0.0 & 0.0 & 0.0 & 0.0 & 0.0 \\
\hline median & 0.0 & 0.0 & 0.0 & 0.0 & 0.0 \\
\hline $75 \%$ percentile & 0.0 & 0.0 & 0.0 & 0.0 & 0.0 \\
\hline zeros $(\%)$ & 87.3 & 85.3 & 78.7 & 73.8 & 81.1 \\
\hline Number of observations & 8,280 & 8,718 & 7,668 & 9,266 & 33,932 \\
\hline
\end{tabular}




\section{Empirical methodology}

The procedure we employ in this paper to estimate the life-cycle consumption profile and the cohort and business cycle effects is similar to the one used in Fernández-Villaverde and Krueger (2007), which in turn builds on work by Deaton and co-authors - see especially Deaton (1997) for a thorough presentation of the methods and issues, besides example applications. The fundamental feature of the methodology is the construction of a "pseudopanel" where the "individual" units correspond to cohorts and the "time" dimension corresponds to the surveys.

The starting point of Deaton's approach is the following model:

$$
E_{i t}=\sum_{c=1}^{N_{c}} \theta_{c} G_{i t}^{c}+\sum_{s=1}^{N_{s}} \gamma_{s} Y_{i t}^{s}+\sum_{a=a_{1}}^{a_{N}} \alpha_{a} A_{i t}^{a}+\epsilon_{i t}
$$

In equation $1, E_{i t}$ is the measure of the expenditure of cohort $i$ according to the survey taken at time $t, G_{i t}^{c}$ is a dummy variable for cohort $c$ which equals 1 when $i=c$ (there are $N_{c}$ cohorts/dummies for cohorts), $Y_{i t}^{s}$ is a dummy variable for survey $s$ which equals 1 when $t=s$ (there are $N_{s}$ surveys/dummies for surveys), $A_{i t}^{a}$ is a dummy variable for age $a$ which equals 1 if the age $\left(A_{i t}\right)$ that individuals (reference persons) belonging to cohort $i$ had when the survey taken at time $t$ occurred was $A_{i t}=a$ (ages in the sample may be between $a_{1}$ and $a_{N}$ ). Regarding the parameters, $\theta_{c}$ is the coefficient that measures the cohort effect corresponding to cohort $c$, while $\gamma_{s}$ measures the time effect corresponding to year $s$. The $\alpha_{a}$ 's show how consumption varies with the age, i.e., over the life cycle.

The approach embodied in equation 1 assumes that the behaviour of consumption reflects three main sources of variation: cohort, time and age. It assumes that, holding everything else constant, consumption of an individual (or household) has a certain profile (given by the $\alpha_{a}$ coefficients) over the lifetime of the individual. That profile reflects the circumstances, the needs and the constraints that typically condition the behaviour of individuals at each age. Equation 1 also assumes that the time of birth (i.e. the cohort) of the individuals may determine the level of lifetime consumption that those individuals will enjoy. In fact, the date of birth influences the time at which individuals enter the labour market, which has been identified in the literature as a determinant of subsequent labour market outcomes (Altonji et al. 2016), and these may impact living standards (although not necessarily - see Cribb et al. 2017). Likewise, equation 1 also allows for a "business cycle" impact on the level of consumption: individuals of all ages/cohorts may adjust their consumption in a certain year (or quarter, if the data is quarterly) in reaction to special circumstances observed in that period. 
Deaton (1997) discusses the difficulties posed by several sources of collinearity in equation 1, that is, the difficulties in identifying the different effects present in that equation. Obviously, each set of dummies (cohorts, surveys and ages) is collinear with any of the other two sets of dummies; in general this would mean that one would have to eliminate one dummy in two of the sets in order to be able to estimate (a version of) equation 1. However, the age reported by the household's reference person in a certain survey is also linearly related to the time of the survey and to the cohort to which that reference person belongs. Specifically, if cohort $i$ refers to individuals that were of age $i$ in a certain base period $t_{0}$, then

$$
A_{i t}=i+t-t_{0}
$$

Equation 2 implies that there is another source of collinearity in the model given by equation 1 which must be addressed. Following Deaton and Paxson (1994), Deaton (1997) suggests imposing a different constraint on the time dummies: make the year effects orthogonal to a linear trend. A consequence of this "normalization" is that the time effects will display a horizontal pattern, around a zero mean, while any growth trends that may exist in the data will emerge in age or cohort effects. In other words, the time effects will behave in a way that may be consistent with a "business cycle" interpretation (even though one might be using annual data).

It is natural that the estimated life-cycle consumption profile - i.e., the plot of the estimated $\alpha_{a}$ 's against the corresponding $a$ 's - may be jagged, contrasting with the smooth curves produced by standard models of consumption behaviour. For instance, Gourinchas and Parker (2002) present both "raw" and "smoothed" estimates of life-cycle consumption profiles in their Figure 2 (p.67).

Fernández-Villaverde and Krueger (2007) prefer to impose smoothness on the life-cycle profile immediately at the estimation stage. Therefore, their starting model may be written as:

$$
E_{i t}=\sum_{c=1}^{N_{c}} \theta_{c} G_{i t}^{c}+\sum_{s=1}^{N_{s}} \gamma_{s} Y_{i t}^{s}+m\left(A_{i t}\right)+\epsilon_{i t}
$$

In equation $3, m(\cdot)$ is a smooth function that will represent the evolution of expenditure over the life cycle of the reference persons, i.e., as a function of the age of the reference person. Fernández-Villaverde and Krueger (2007) employ a non-parametric approach to estimate function $m(\cdot)$, proposed by Speckman (1988). Fernández-Villaverde and Krueger (2007) also make use of the normalization discussed in Deaton (1997) for time effects. In this paper we also follow this procedure. 
However, our empirical procedure will differ from the procedure employed by Fernández-Villaverde and Krueger (2007) in two regards. First, in the case of expenditure on health, we do not take the logarithm of the measure of consumption (the dependent variable). Note that Deaton (1997) also works with levels rather than logarithms. Second, we use the median instead of the mean of the measure of consumption. Both these differences with respect to Fernández-Villaverde and Krueger (2007) are related to the fact that there are many zeros in our data, besides some extremely large values - recall section 2 . The median mitigates the influence of those observations. Given this, in our empirical application $E_{i t}$ will be the median in period $t$ of the consumption expenditure (in logarithms except in the case of health expenditure) of those households whose reference person belongs to cohort $i$.

Since we will devote special attention to cohort and time effects - to which Fernández-Villaverde and Krueger (2007) make only a passing reference -we also need to be clear about the additional restriction required to identify age and cohort effects. We chose to omit the dummy corresponding to the youngest cohort in our sample. In other words, we set its coefficient equal to zero. This has two implications. First, the coefficients of the other cohorts will measure the average difference between the consumption level of those cohorts and the consumption level of the youngest cohort. Second, the level of the estimated life-cycle profile will portray the consumption level of the youngest cohort. Note that we employ the term "youngest cohort" to refer to the cohort that was born more recently. Given that the last survey refers to 2015 and that we restrict our attention to reference persons' aged between 25 and 74, the youngest cohort is the cohort born in 1990 .

The approach to the identification of cohort, business-cycle and life-cycle effects that we have described in this section is based on an assumption that has a distinct economic flavour to it: trend versus cycle. Fukuda (2006) contrasts this "econometric" approach with the purely "statistical" approach analyzed in Nakamura (1986). Nakamura's approach is Bayesian in nature: first one chooses a prior distribution for the parameters of interest (i.e., the cohort, business-cycle and life-cycle effects) and then the distribution is updated given the data. The estimate of the parameters is the mode of the posterior distribution. Importantly, the procedure also imposes the assumption that the various effects are smooth over time. In other words, whereas the Fernández-Villaverde and Krueger (2007) procedure, by employing a non-parametric method, imposes smoothness only on the estimated life-cycle component, the Nakamura (1986) procedure imposes smoothness on all components. An alternative approach would be to define each cohort as corresponding to an interval of years rather than to a single year - see, e.g., Grossbard and Amuedo-Dorantes (2007). In this case, perfect smoothness is 
imposed across the years included in each cohort, but jumps may occur from one cohort to the next.

\section{Estimated life-cycle profiles, cohort and busi- ness cycle effects}

In this section we present the results from applying the procedure described in the previous section to our dataset. We begin by reporting estimates for the behaviour of consumption over the life cycle of Portuguese households. We then compare our results with those reported in the literature for other countries. Finally, we discuss the corresponding cohort and business cycle effects.

\subsection{Life-cycle consumption profiles}

Figure 1 shows the estimated life-cycle profiles for total expenditure, nondurables, durables and health expenditures.

Total yearly expenditure is increasing until the household's reference person's age is in the 40's. The increase between consumption at age 25 and consumption when the reference person's age is in the 40's is about $13 \%$, from 20.5 thousand euros to 23.3 thousand euros. While the reference person's age is in the 40's, consumption is very flat. After the reference person reaches the age of 50, household expenditure slowly declines - until the age of 74 , the decline is almost $40 \%$ (from 23.3 thousand euros to 14.5 thousand euros). The size of the hump that we report here for Portuguese households is much smaller than that reported by Fernández-Villaverde and Krueger (2007) for the USA (which is around 80\% larger at the peak, in the mid-40's, than in the early 20 's). In the US data, the following decrease in consumption (around a $50 \%$ decrease from the peak) is also more pronounced than the decrease estimated by us.

Nondurables consumption is almost flat until the late 40's. Afterwards it decreases steadily, and at the age of 74 the decrease is half of the peak. The magnitude of this decline is slightly less than that reported by FernándezVillaverde and Krueger (2007), but again, in their case, it is preceded by a significant increase, which does not seem to occur in Portuguese household nondurable consumption.

The estimated behaviour of durable consumption by Portuguese households over the life cycle is also at odds with the results presented in FernándezVillaverde and Krueger (2007). Our results show that durable consumption 
Figure 1: Life-cycle profiles
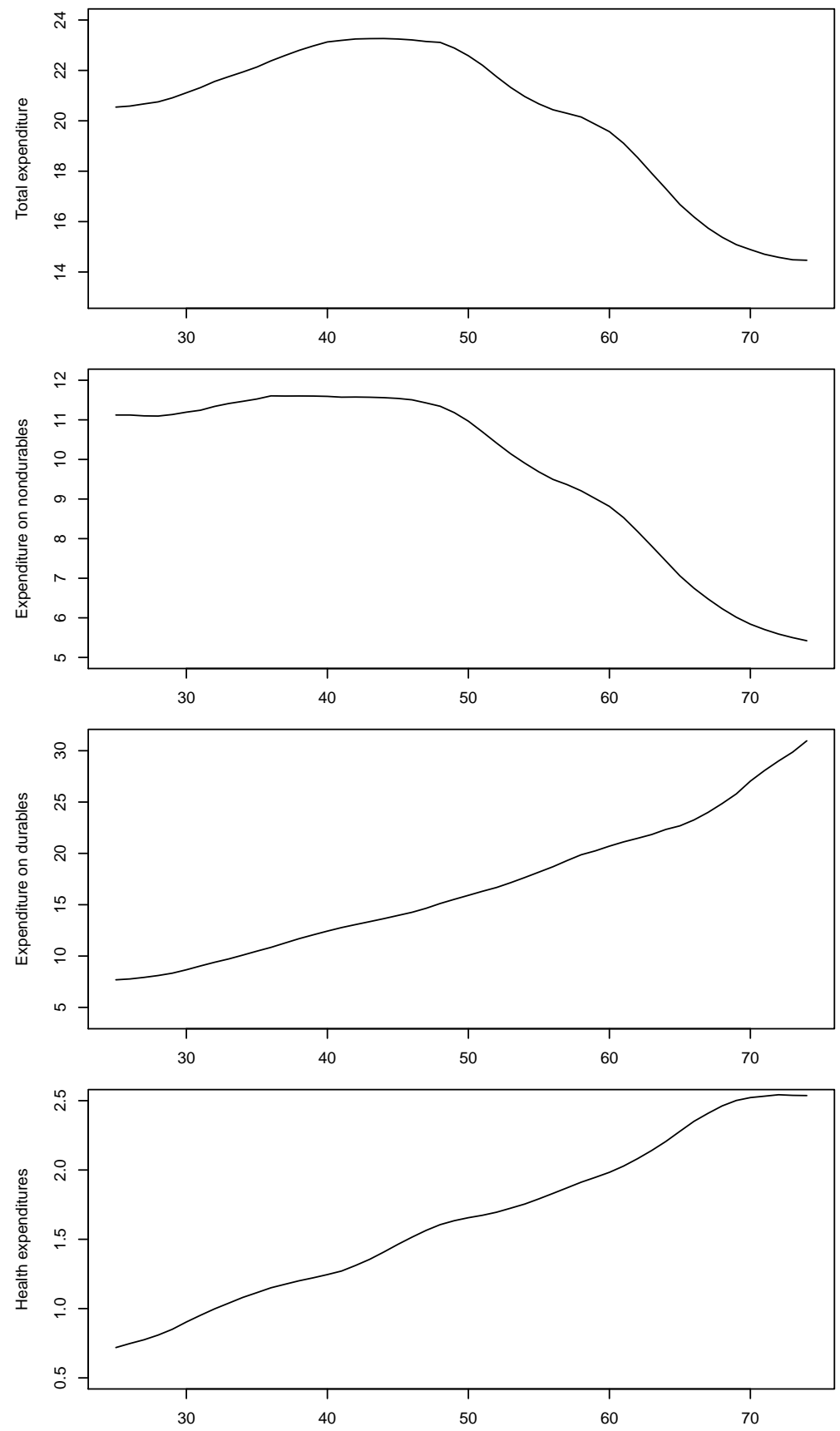

Notes: Thousands of 2015 euros. The variable in the horizontal axis is age. 
steadily rises over the life cycle (the increase of durable consumption between the age of 25 and the age of 74 is $300 \%$, from 7.7 to 31 thousand euros), whereas in Fernández-Villaverde and Krueger (2007) there is a clear hump, similar to the hump in nondurable consumption.

Economic theory usually makes predictions for the behaviour of per person consumption rather than household consumption. Therefore we also estimated adult-equivalent life-cycle consumption profiles, which should provide a firmer ground on which to discuss explanations for the observed differences between the consumption profiles for households in Portugal and in other countries. Following Fernández-Villaverde and Krueger (2007), adult equivalent consumption is obtained using the mean of a set of equivalence scales previously proposed in the literature. Namely, we take the mean of the equivalence scales proposed by OECD, the Panel on Poverty and Family Assistance of the National Academy of Sciences, the Department of Health and Human Services, the Department of Commerce, the Lazear and Michael equivalence scale, and the Nelson equivalence scale. For further details and references, see the discussion in Fernández-Villaverde and Krueger (2007), who put special emphasis on this issue. More recent studies on this issue include Balli and Tiezzi (2010) and Bütikofer and Gerfin (2017).

When we adjust total expenditure for the size of the household using the mean equivalence scale of Fernández-Villaverde and Krueger (2007), the lifecycle profile becomes even flatter: the relative change from the beginning until the peak is now $11 \%$ instead of $13 \%$ - see Figure 2. After the peak, total expenditure declines by around 6\%. Our estimates are in contrast with the results obtained by Fernández-Villaverde and Krueger (2007) in the sense that they continue to find a significant hump in adult equivalent consumption (household size explains only about half of the hump in the US data), whereas in our data the profile becomes almost perfectly flat. Therefore, our estimated life-cycle profiles are closer to the predictions of the standard life-cycle model than the profiles reported in Fernández-Villaverde and Krueger (2007) — we discuss possible explanations in the final section of the paper as a starter for further research. Nevertheless, we still find a small hump in total expenditure, which peaks when the individual is around 60 years old. Our results for the Portuguese case are supported by the results presented in Alves and Cardoso (2010) and Banco de Portugal (2018), which are based on a cross-section of data, for 2005 and 2015, respectively.

Regarding nondurable consumption, the adjustment for household size also produces an even flatter profile. The estimated profile is extremely flat until the late 40's and then slightly decreasing: by age 74 the cumulated decrease from the peak is $27 \%$ (from 8.2 to 6 thousand euros). Again, this differs from the results in Fernández-Villaverde and Krueger (2007), where 
Figure 2: Life-cycle profiles - adult equivalent
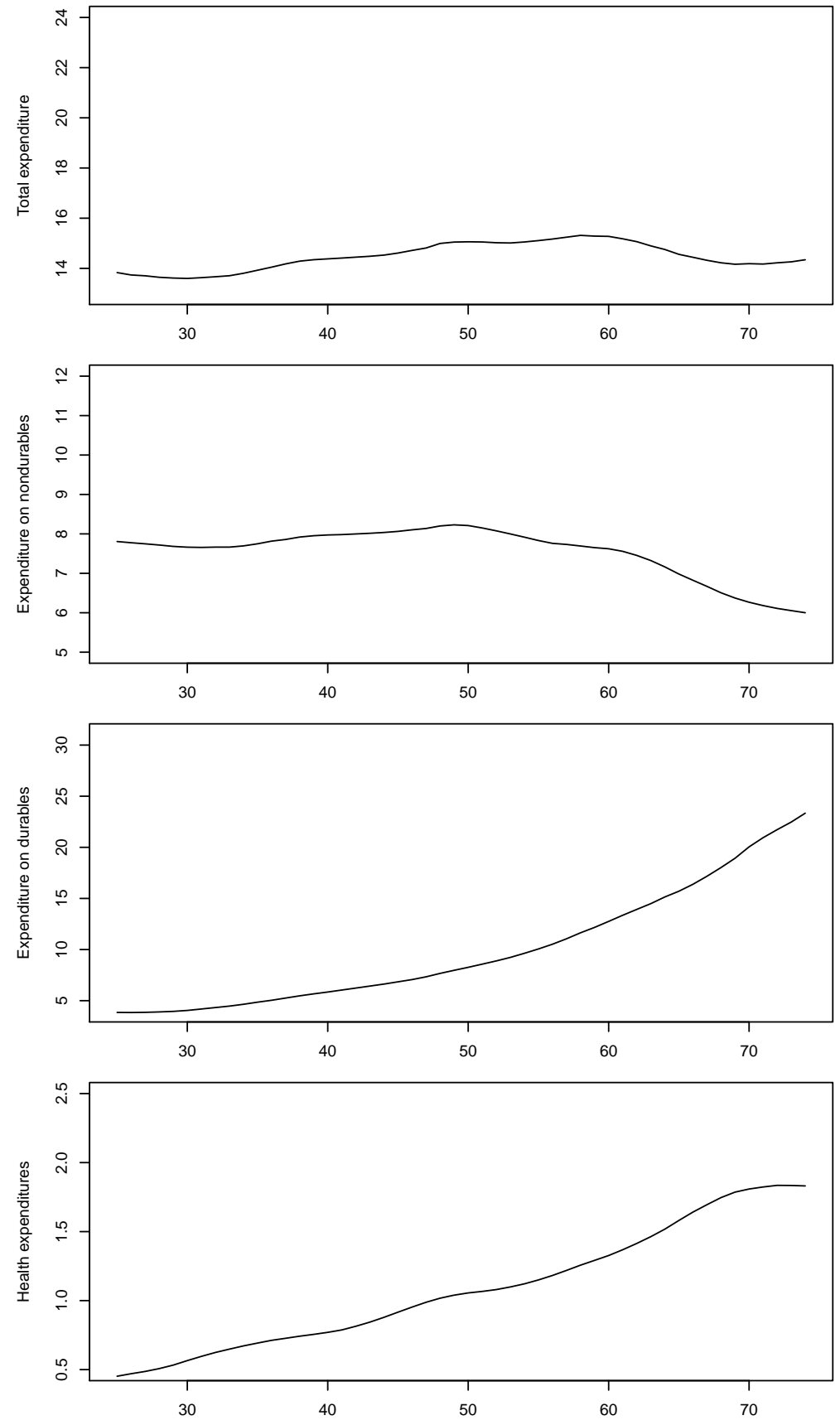

Notes: Thousands of 2015 euros. The variable in the horizontal axis is age. 
the adult equivalent nondurable profile still displays a very significant hump. Our results are also very different from those reported for the Netherlands by Alessie and Ree (2009). Alessie and Ree (2009) estimate that the life-cycle profile of nondurable consumption is increasing over the lifetime, whereas durable consumption decreases between age 60 and age 75 by about $40 \%-$ see their Figure 5. Gourinchas and Parker (2002) and Aguiar and Hurst (2013) also observe a substantial increase in nondurable consumption until age 45, although the magnitude of the subsequent fall appears to be similar (around 25\%). For the UK, Banks et al. (2016) estimate a much larger decline $(45 \%)$ between ages 45 and 75 . However, given the components of nondurable expenditure in our study (e.g., food, transport services - recall section 2), the flatness of the profile is not surprising. This sort of expenditure is not expected to vary much while the individuals are in the labour force, but naturally decreases as the individual grows old and/or leaves the labour force.

We also find that the adult equivalent profile for durable consumption is steeper than the unadjusted profile. In the adjusted profile, the increase in durable consumption over the life cycle is $500 \%$, clearly larger than the $300 \%$ increase reported for the unadjusted profile. The behaviour of durable expenditure by Portuguese households may be related to the fact that households typically move to larger dwellings as the family size increases (or as the children grow), with the goal of having more space to accommodate the household members - see Table 1. However, it is still unusual for households to move to smaller dwellings after the children move out. This implies that the per person expenditure on housing will increase for older households. Another implication of not moving to a new dwelling may be the increase in repair/maintenance expenditure required by older dwellings - this may also help explain the increase in durable expenditure per person. In FernándezVillaverde and Krueger (2007) the adult equivalent durable expenditure decreases by a large proportion after the mid-40's peak. The difference between that result and the result we obtained for Portuguese households may be related to the greater mobility of US households and the more dynamic US housing market. An alternative explanation for the observed trend in durable consumption in the case of Portuguese households may be the fact that ownership of a broader range of household appliances has only recently become common. Therefore, the estimated upward trend in durable consumption may also in part be a reflection of that increased access to home appliances, also driven by the increasing importance of technological devices, such as smart phones and computer equipment.

Portugal's population is ageing rapidly. This will have consequences for healthcare needs. Therefore, we believe it is interesting to see what the 
methodology employed in this paper says about the life cycle of expenditure on health by Portuguese households. The estimated lifetime profile for health expenditure is increasing over the lifetime-bottom panel of Figure 2. A young household will spend around 700 euros on health, whereas a household with a reference person over 70 years old will spend about 2.5 thousand euros, that is, 3.5 times more. In adult equivalent terms, the evolution is from less than 500 euros to 2.5 thousand euros (five times more). This increasing lifetime profile is what one would expect, given the well-known additional healthcare needs of older people.

\subsection{Cohort effects}

As in other European countries and in the USA — see Gordon (2016) — , Portugal went through a rapid process of structural transformation and strong economic growth during the twentieth century. However, relative to countries in Central and Northern Europe, Portugal was a late developer. A democratic regime was instituted only in the late 1970s and accession to the European Union took place only in 1986. Membership of the European Union changed many aspects of life in Portugal, in particular consumption standards, which became similar to those in the most advanced countries. Therefore, it is important to analyze the impact of that evolution on the well-being of different cohorts (as indicated by the median). Cohorts born during the dictatorship, in a closed economy, will show different consumption behaviours than cohorts born after 1970, which grew up in a democratic regime and identify themselves as Europeans.

In this section we report and discuss our estimates of the cohort effectssee Figure 3. Adjusting for the size of the household does not affect the general features of the life-cycle consumption profiles; therefore we only report estimates for the adult equivalent cases.

For total expenditure and nondurable expenditure, the cohort effects show a similar pattern. Cohorts born before the 1940's on average attain a clearly lower consumption level. The higher level of (median) consumption standards of post-war generations reflects the modernization and high growth rates of the Portuguese economy.

Total expenditure shows a slightly increasing trend for the consumption of post-war generations. This trend appears to be related to the increase in consumption of durables and, to a less extent, in health expenditure. These two categories show a different pattern for the cohort effects. In fact, the pattern for these categories is that of a clear upward trend - each new generation appears to have had a higher (median) standard of consumption of durables and healthcare than the previous generation. Alessie and Ree 
Figure 3: Cohort effects - adult equivalent
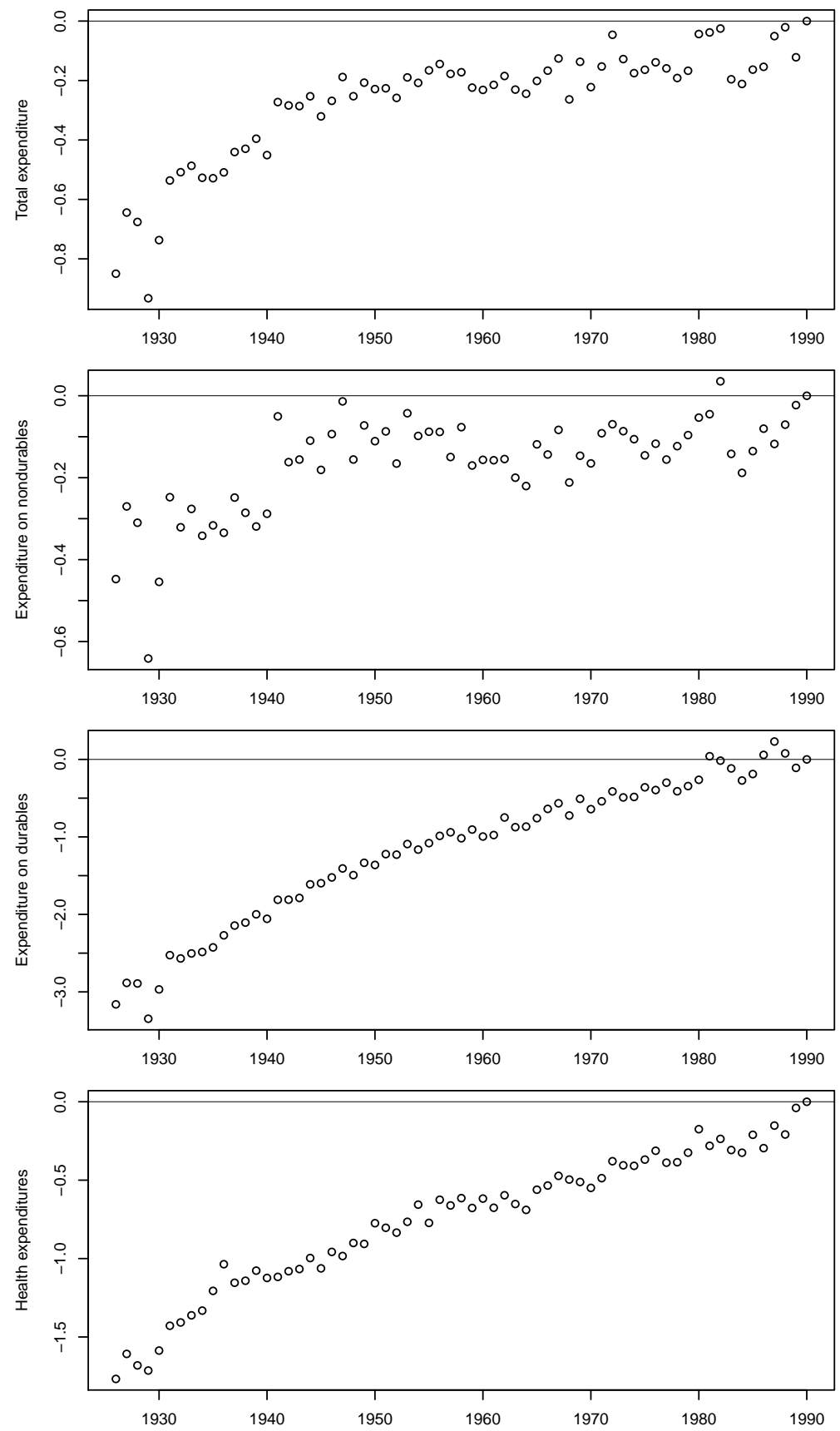

Notes: Thousands of 2015 euros. The variable in the horizontal axis is the year of birth of the cohort. 
(2009) found similar patterns for the Netherlands.

\subsection{Business cycle effects}

Consumption is highly persistent but it is not immune to the business cycle. During the period spanned by the surveys used in our dataset, the Portuguese economy went through several periods of recession and expansion. Therefore we should take into account the effect of these oscillations on the level of consumption.

Our discussion of business cycle effects on consumption levels is limited by the number of surveys on which our analysis is based. We can only estimate business cycle effects for the years of the surveys: 2000, 2005, 2010 and 2015. The estimated effects (again referring to the results for the adult equivalent series) are presented in Figure 4. In our view, the most striking feature of the business cycle effects reported is the positive effect on consumption in 2010 and the sharp fall in 2015. Countercyclical fiscal policy in 2009-2010 mitigated the impact of the international financial crisis that started in late 2007 in the USA and reached Europe in late 2008. In Portugal, the 2009 recession was milder than in the rest of the European Union and the real GDP growth rate was $1.8 \%$ in 2010 . The size of the budget deficits (and the increase in public debt) in 2009-2010 led to a sudden stop and to the bailout by the International Monetary Fund, the European Commission and the European Central Bank. The adjustment that followed implied a strong contraction in economic activity: from 2010 to 2013, real GDP fell by 7\%. In 2015, real GDP was still 4\% below the 2010 level.

\section{Concluding Remarks}

In this paper we report and discuss estimates of life-cycle consumption profiles obtained using microdata for Portuguese households. The estimated profiles are much flatter than the profiles usually reported in the literature for other countries, namely the Netherlands, the UK and the USA. There are several possible explanations for the similarity between our results and the predictions of the basic life-cycle theory of consumption.

First, the development of financial markets provided young people with access to credit. Given the usual profile of lifetime income, access to credit is a necessary condition for the flatness of the consumption profile. One of the major transformations observed in the Portuguese economy in recent decades was the liberalization of the financial system and the consequent increase in access to credit by households - see Antão et al. (2009) and Banco de 
Figure 4: Year effects - adult equivalent
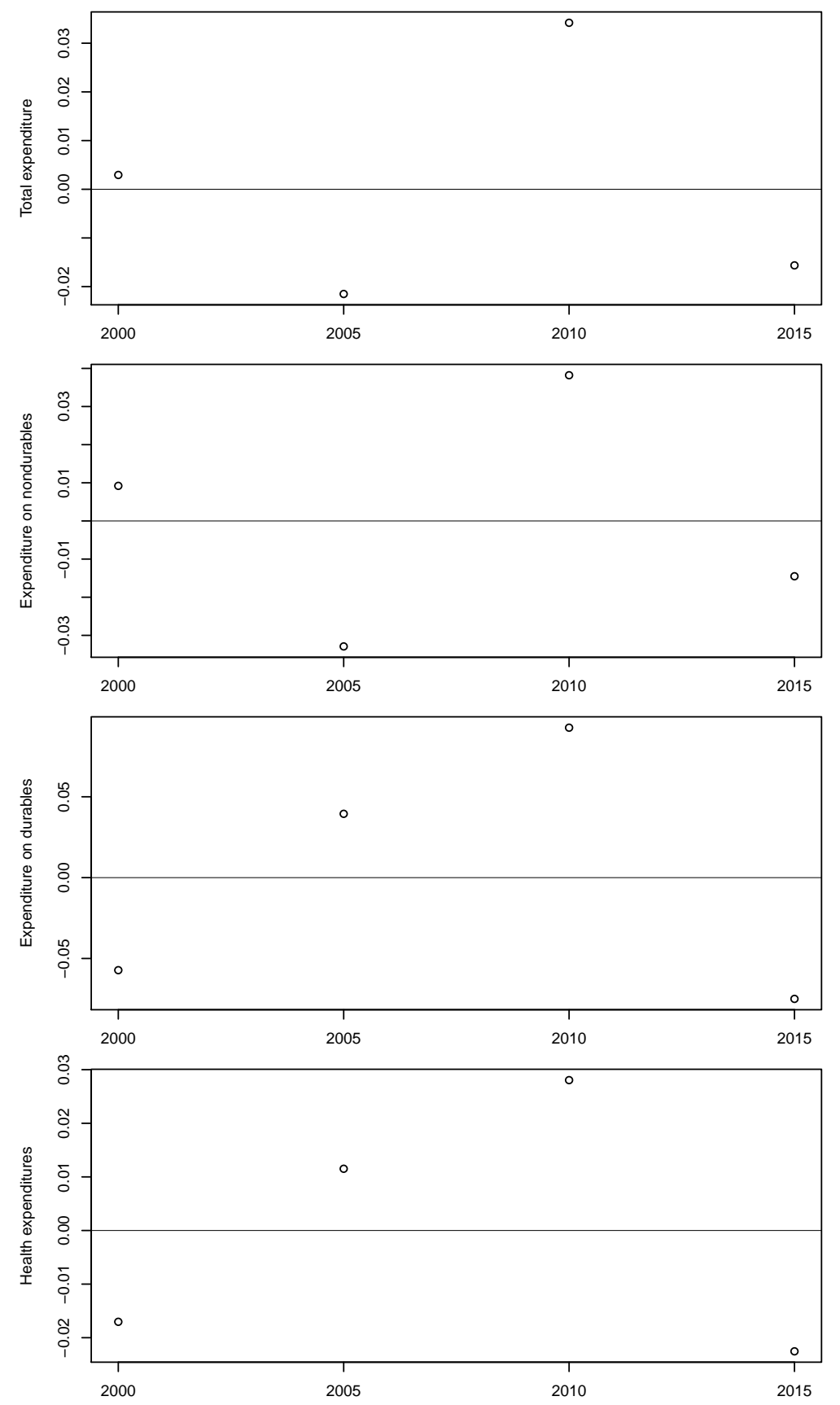

Notes: Thousands of 2015 euros. The variable in the horizontal axis is the year of the survey. 
Portugal (2009). Castro (2006) associates this liberalization to a significant decrease in the proportion of credit constrained households in Portugal during the 1990s. Castro (2007) estimates that as a result Portuguese households have become less keynesian and more forward looking, i.e., consumption has become less sensitive to current income and more sensitive to wealth. Farinha (2009) also estimates a significant wealth effect on consumption, but using data from three cross-sections. Our results may be viewed as consistent with the conclusions reached in these papers. The hypothesis that the flatness of the consumption profile is related to the liberalization of financial markets is also consistent with our estimates for durable and nondurable expenditures. Reduced credit constraints should be reflected in an increasing cohort effect in the case of durable consumption, but in the case of nondurable consumption no significant impact should be observed. This is what our results show: in Figure 3 there is an upward trend in durable consumption and a flat profile for nondurable consumption. In addition to the lifting of liquidity constraints, access to mortgage credit by young households was also facilitated by public subsidies. The subsidies program (Crédito Bonificado) is analyzed in Martins and Villanueva (2006), who report that this program became so important that in 1998 two out of three new euros of mortgage debt were borrowed under its rules.

Countries for which a hump-shaped consumption profile has been found also enjoy developed financial markets. Therefore, although developed financial markets help smooth consumption, they do not provide an explanation of the difference between the consumption profiles estimated for Portugal and for other countries such as the USA. A fact that may explain the difference the Portuguese and the US consumption profiles is the existence of a generous and predictable pensions system, that reduced the probability of abrupt drops in income around retirement. Actually, under the rules that were in place until recently, income post-retirement might even exceed pre-retirement income - see OECD (2007). The rules were changed by a reform of the social security system that was introduced in 2007 to curb expenditure on pensions, and new pensioners are now facing cuts in their income when they move into retirement. The fall in income, which is commonly associated with the postretirement drop in consumption in other countries, is therefore likely to be less important in Portugal in the sample that we are using. Coupled with the labour market rigidity that characterized the Portuguese economy (at least certain segments of that labour market), the pensions system contributed to make the lifetime income forecastable, namely for public servants. This had two consequences: individuals faced few risks and were more inclined to borrow; financial institutions also viewed those individuals as low-risk customers and therefore were more prone to lend to them. More generally, the 
protection provided by the Portuguese welfare state means households do not need to save as much as in the USA to secure access to health and education services - see Palumbo (1999) and De Nardi et al. (2010).

Finally, an alternative hypothesis is that the composition of households may also contribute to the observed consumption smoothing. In Southern European countries, the offspring tend to continue to live with the parents for longer than in Northern Europe. According to the Statistical Office of the European Communities (2015), in 2013, the mean age of leaving the parental home was higher than 28 in Bulgaria, Croatia, Greece, Italy, Malta, Poland, Portugal, Romania, Spain, Slovakia and Slovenia. On the other hand, in Sweden, Denmark and Finland, young people left the parental home, on average, before the age of 23, and at the age of 24 in the Netherlands and in France. ${ }^{2}$ The same report reveals that, in Portugal, around $60 \%$ of men aged between 25 and 29 years old still lived with their parents. One possible interpretation of this behaviour is that in Southern Europe young people only leave the parents' home when they achieve a level of income that allows them to maintain the same level of consumption on their own, which will result in a flatter consumption profile. Consumption smoothing may therefore be achieved inside a household by the sharing of resources between the older and the younger adults in that household. If this hypothesis is correct, the family should also be understood as a mechanism of consumption smoothing. The results reported in Di Stefano (2019) are consistent with this hypothesis. Di Stefano (2019) concludes that Italian youths choose to leave their parents' house late because of poor labor market conditions and high housing costs, with the parents' income functioning as an insurance against unemployment.

The flatness of the life-cycle consumption profile estimated for Portugal, relative to other countries, is a surprising result in the context of the related literature. We discussed three hypothesis that may help explain it. Proper evaluation of their relevance requires future investigation. Given the low saving rate of Portuguese households, and the macroeconomic implications of that behaviour, it is very important to identify the determinants of the life-cycle consumption profile of Portuguese households.

\section{References}

Aguiar, M. and E. Hurst (2013). Deconstructing life cycle expenditure. Journal of Political Economy 121(3), 437-492.

\footnotetext{
${ }^{2}$ Alternative perspectives on this issue can be found in Chiuri and Boca (2010), Angelini and Laferrère (2013) and Ahn and Sánchez-Marcos (2017).
} 
Ahn, N. and V. Sánchez-Marcos (2017, June). Emancipation under the great recession in Spain. Review of Economics of the Household 15(2), $477-495$.

Alessie, R. and J. Ree (2009, March). Explaining the hump in life cycle consumption profiles. De Economist 157(1), 107-120.

Alexandre, F., L. Aguiar-Conraria, P. Bação, and M. Portela (2017). Poupança e Financiamento da Economia Portuguesa. Lisboa: Imprensa Nacional Casa da Moeda.

Altonji, J. G., L. B. Kahn, and J. D. Speer (2016). Cashier or consultant? Entry labor market conditions, field of study, and career success. Journal of Labor Economics 34(S1), S361-S401.

Alves, N. and F. Cardoso (2010). Household saving in Portugal: Micro and macroeconomic evidence. Economic Bulletin. Banco de Portugal (Winter), $47-67$.

Angelini, V. and A. Laferrère (2013, September). Parental altruism and nest leaving in Europe: evidence from a retrospective survey. Review of Economics of the Household 11(3), 393-420.

Antão, P., M. Boucinha, L. Farinha, A. Lacerda, A. C. Leal, and N. Ribeiro (2009). Financial integration, financial structures and the decisions of households and firms. In Banco de Portugal (Ed.), The Portuguese Economy in the Context of Economic, Financial and Monetary Integration, Chapter 7, pp. 415-545. Lisbon: Banco de Portugal.

Attanasio, O. P. (1998). Cohort analysis of saving behavior by U.S. households. Journal of Human Resources 33(3), 575-609.

Attanasio, O. P. and G. Weber (1995, December). Is consumption growth consistent with intertemporal optimization? Evidence from the Consumer Expenditure Survey. Journal of Political Economy 103(6), 11211157.

Attanasio, O. P. and G. Weber (2010, September). Consumption and saving: Models of intertemporal allocation and their implications for public policy. Journal of Economic Literature 48(3), 693-751.

Baldwin, R., T. Beck, A. Bénassy-Quéré, O. J. Blanchard, G. Corsetti, P. D. Grauwe, W. D. Haan, F. Giavazzi, D. Gros, S. Kalemli-Ozcan, S. Micossi, E. Papaioannou, P. Pesenti, C. Pissarides, G. Tabellini, and B. W. di Mauro (2015). Rebooting the Eurozone: Step 1 - agreeing a crisis narrative. CEPR Policy Insight 85, Centre for Economic Policy Research. 
Balli, F. and S. Tiezzi (2010, December). Equivalence scales, the cost of children and household consumption patterns in Italy. Review of Economics of the Household 8(4), 527-549.

Banco de Portugal (2009). The Portuguese Economy in the Context of Economic, Financial and Monetary Integration. Lisboa: Banco de Portugal.

Banco de Portugal (2018). Household consumption inequality in Portugal. Economic Bulletin. Banco de Portugal (June), 53-72.

Banks, J., R. Blundell, P. Levell, and J. P. Smith (2016, August). Lifecycle consumption patterns at older ages in the US and the UK: Can medical expenditures explain the difference? NBER Working Papers 22513, National Bureau of Economic Research, Inc.

Banks, J., R. Blundell, and S. Tanner (1998, September). Is there a retirement-savings puzzle? American Economic Review 88(4), 769788 .

Browning, M. and T. F. Crossley (2001, Summer). The life-cycle model of consumption and saving. Journal of Economic Perspectives 15(3), $3-22$.

Bütikofer, A. and M. Gerfin (2017, June). The economies of scale of living together and how they are shared: estimates based on a collective household model. Review of Economics of the Household 15(2), 433453.

Castro, G. L. (2006). Consumption, disposable income and liquidity constraints. Economic Bulletin. Banco de Portugal (Summer), 75-84.

Castro, G. L. (2007). The wealth effect on consumption in the Portuguese economy. Economic Bulletin. Banco de Portugal (Winter), 37-55.

Chiuri, M. and D. D. Boca (2010, September). Home-leaving decisions of daughters and sons. Review of Economics of the Household 8(3), 393-408.

Cribb, J., A. Hood, and R. Joyce (2017, November). Entering the labour market in a weak economy: scarring and insurance. IFS Working Papers W17/27, Institute for Fiscal Studies.

De Nardi, M., E. French, and J. B. Jones (2010, February). Why do the elderly save? The role of medical expenses. Journal of Political Economy 118(1), 39-75.

Deaton, A. (1997). The analysis of household surveys: A microeconometric approach to development policy. Washington, D.C.: The World Bank. 
Deaton, A. S. and C. Paxson (1994, June). Saving, growth, and aging in Taiwan. In Studies in the Economics of Aging, NBER Chapters, pp. 331-362. National Bureau of Economic Research, Inc.

Di Stefano, E. (2019, March). Leaving your mamma: why so late in Italy? Review of Economics of the Household 17(1), 323-347.

Eurostat (2003). Household budget surveys in the EU - Methodology and recommendations for harmonisation 2003. Luxembourg: Office for Official Publications of the European Communities.

Farinha, L. (2009). Wealth effects on consumption in Portugal: A microeconometric approach. Economic Bulletin and Financial Stability Report Articles and Banco de Portugal Economic Studies.

Fernández-Villaverde, J. and D. Krueger (2007, August). Consumption over the life cycle: Facts from consumer expenditure survey data. The Review of Economics and Statistics 89(3), 552-565.

Fukuda, K. (2006, December). A cohort analysis of female labor participation rates in the U.S. and Japan. Review of Economics of the Household 4 (4), 379-393.

Gordon, R. (2016). The Rise and Fall of American Growth: The U.S. Standard of Living since the Civil War. The Princeton Economic History of the Western World. Princeton, New Jersey: Princeton University Press.

Gourinchas, P.-O. and J. A. Parker (2002, January). Consumption over the life cycle. Econometrica 70(1), 47-89.

Grossbard, S. and C. Amuedo-Dorantes (2007, September). Cohort-level sex ratio effects on women's labor force participation. Review of Economics of the Household 5(3), 249-278.

INE (2017). Inquérito às Despesas das Famílias 2015/2016. Lisboa: Instituto Nacional de Estatística.

Jappelli, T. (1999, March). The age-wealth profile and the life-cycle hypothesis: A cohort analysis with time series of cross-sections of Italian households. Review of Income and Wealth 45(1), 57-75.

Lim, G. C. and Q. Zeng (2016, September). Consumption, income, and wealth: Evidence from age, cohort, and period elasticities. Review of Income and Wealth 62(3), 489-508.

Martins, N. C. and E. Villanueva (2006, September). The impact of mortgage interest-rate subsidies on household borrowing. Journal of Public Economics 90(8-9), 1601-1623. 
Nakamura, T. (1986, December). Bayesian cohort models for general cohort table analyses. Annals of the Institute of Statistical Mathematics 38(2), 353-370.

OECD (2007). Pensions at a Glance 200\%: Public Policies across OECD Countries. Paris: OECD Publishing.

Palumbo, M. G. (1999). Uncertain medical expenses and precautionary saving near the end of the life cycle. The Review of Economic Studies 66(2), 395-421.

Passero, W., T. I. Garner, and C. McCully (2014). Understanding the relationship: CE survey and PCE. In C. D. Carroll, T. F. Crossley, and J. Sabelhaus (Eds.), Improving the Measurement of Consumer Expenditures, pp. 181-203. University of Chicago Press.

Reis, R. (2013). The Portuguese slump and crash and the euro crisis. Brookings Papers on Economic Activity 44 (1 (Spring)), 143-210.

Speckman, P. (1988). Kernel smoothing in partial linear models. Journal of the Royal Statistical Society. Series B (Methodological) 50(3), 413-436.

Statistical Office of the European Communities (2015). Being young in Europe today.

Zhou, S. (2012). Explaining the saving puzzles in urban China. Review of Income and Wealth 58(3), 504-530. 


\section{Appendices}

\section{A Classification of household expenditures}

In this paper we follow the approach of Fernández-Villaverde and Krueger (2007) in dividing total expenditure among five categories: nondurables, durables, health, clothing and footwear, and education. For the last three categories we used the corresponding categories in the Portuguese Household Budget Survey (IDEF). We then classified the remaining categories in IDEF as either durable or nondurable expenditure. Our classification is presented in Table A.1.

However, as a result of differences in the classification of household expenditures, comparison of our results with results presented in other papers in the literature is not straightforward. While the IDEF uses the United Nations' Classification of Individual Consumption According to Purpose (COICOP), the Consumer Expenditure Survey (CEX) data used by Fernández-Villaverde and Krueger (2007) does not. Passero et al. (2014) provide a thorough discussion of the relationship between these data and the 'Personal consumption expenditures' (PCE) data, released by the US Bureau of Economic Analysis, which is based on the COICOP. Their discussion is helpful for understanding the problems arising when comparing studies that use different classifications of expenditures.

The major difference between our categories and those in FernándezVillaverde and Krueger (2007) concerns Education. In IDEF this category includes only fees (tuition and administrative). Other education related expenditures are considered to be part of other categories. Most notably, books are part of recreation and culture expenditures, while school transportation is part of transport services. In CEX, these expenditures (and others such as "Food or board while attending school") are included in the Education category.

In Fernández-Villaverde and Krueger (2007) expenditures on durables include owned dwelling, rented dwelling, house equipment, vehicles, books and electronic equipment. Our measure expands on this by including insurances connected with dwelling. Note that according to Passero et al. (2014, p. 192), the PCE (COICOP) measures of insurance do not match those in CEX. Likewise, our classification of expenditure on nondurables includes, for example, social protection, travel insurance, other insurance or financial services, but the COICOP definition of these items also does not match that in CEX.

IDEF includes the major components of health expenditure, as the CEX does. However, a significant part of the Portuguese population has access 
to the National Health Service for free. Over time, free access has been restricted, which may help explain the decreasing frequency of zero values in the sample- see Table 4.

Table A.1: IDEF - expenditure category codes

\begin{tabular}{|c|c|c|}
\hline Category & Subcategory & Code \\
\hline Health & & $(06)$ \\
\hline Clothing and footwear & & $(03)$ \\
\hline Education & & $(10)$ \\
\hline \multicolumn{3}{|c|}{ Durables } \\
\hline \multirow{4}{*}{$\begin{array}{l}\text { Housing, water, elec- } \\
\text { tricity, Gas and other } \\
\text { fuels } \\
\text { Furnishings, house- } \\
\text { hold equipment and } \\
\text { routine maintenance } \\
\text { of the house }\end{array}$} & Actual rentals for housing & $(04.1)$ \\
\hline & Imputed rentals for housing & $(04.2)$ \\
\hline & Maintenance and repair of the dwelling & $(04.3)$ \\
\hline & & $(05)$ \\
\hline \multirow{6}{*}{$\begin{array}{l}\text { Transports } \\
\text { Communications } \\
\text { Recreation, Sport and } \\
\text { Culture } \\
\text { Other goods and ser- } \\
\text { vices }\end{array}$} & Purchase of vehicles & $(07.1)$ \\
\hline & Telephone and telefax equipment & $(08.2)$ \\
\hline & Audiovisual, photographic and information processing equipment & $(09.1)$ \\
\hline & Other major durables for recreation and culture & $(09.2)$ \\
\hline & Insurance connected with the dwelling & $(12.52)$ \\
\hline & Insurance connected with transport & $(12.541)$ \\
\hline \multicolumn{3}{|c|}{ Nondurables } \\
\hline \multirow{6}{*}{$\begin{array}{l}\text { Food and non- } \\
\text { alcoholic beverages } \\
\text { Alcoholic beverages, } \\
\text { tobacco and narcotics } \\
\text { Housing, water, elec- } \\
\text { tricity, Gas and other } \\
\text { fuels } \\
\text { Transports }\end{array}$} & & $(01)$ \\
\hline & & $(02)$ \\
\hline & Water supply and miscellaneous services relating to the dwelling & $(04.4)$ \\
\hline & Electricity, gas and other fuels & $(04.5)$ \\
\hline & Operation of personal transport equipment & $(07.2)$ \\
\hline & Transport services & $(07.3)$ \\
\hline \multirow{5}{*}{$\begin{array}{l}\text { Communications } \\
\text { Recreation, Sport and } \\
\text { Culture } \\
\text { Restaurants and ho- } \\
\text { tels }\end{array}$} & Postal services & $(08.1)$ \\
\hline & Telephone and telefax services & $(08.3)$ \\
\hline & Other recreational items and equipment, gardens and pets & $(09.3)$ \\
\hline & Newspapers, books and stationery & $(09.5)$ \\
\hline & & (11) \\
\hline \multirow{8}{*}{$\begin{array}{l}\text { Other goods and ser- } \\
\text { vices }\end{array}$} & Personal care & $(12.1)$ \\
\hline & Prostitution & $(12.2)$ \\
\hline & Personal effects n.e.c. & $(12.3)$ \\
\hline & Social protection & $(12.4)$ \\
\hline & Travel insurance & $(12.542)$ \\
\hline & Other insurance & $(12.55)$ \\
\hline & Financial services n.e.c. & $(12.6)$ \\
\hline & Other services n.e.c. & $(12.7)$ \\
\hline
\end{tabular}

Notes. See INE (2017) and Eurostat (2003) for further detail on the categories. Total expenditure equals the sum of expenditure on Durables, expenditure on Nondurables, expenditure on Health, expenditure on Clothing and footwear and expenditure on Education.

\section{B Imputation of age}

Our IDEF dataset only contains the age of the household's reference person for the 2010 survey. For the other surveys, we know the age class of the 
reference person. In the cases of the 2000 and 2015 surveys, the age classes are five years long, from [25;29] until [70;74]. In the case of the 2005 survey, the age classes are $[25 ; 29],[30 ; 44],[45 ; 64]$ and $[65 ; 74]$. Therefore, we used two versions of the multinomial logit model for imputing the age, one for the 2000 and 2015 surveys, the other for the 2005 survey.

The multinomial logit model assumes that, given $J$ possible values $\left(V_{j}\right)$ for the outcome variable $Y_{i}$ (the value taken for individual $i$ ), the probability of observing alternative $j$ is given by:

$$
P\left(Y_{i}=V_{j} \mid \mathbf{x}_{i}\right)=\frac{\exp \left(\mathbf{x}_{i}^{\prime} \boldsymbol{\beta}_{j}\right)}{\sum_{k=1}^{J} \exp \left(\mathbf{x}_{i}^{\prime} \boldsymbol{\beta}_{k}\right)}
$$

where $\mathbf{x}_{i}$ is a vector of characteristics of individual $i$ and $\boldsymbol{\beta}_{j}(j=1, \ldots, J)$ is the matching vector of coefficients corresponding to alternative $j$. To identify the coefficients, a normalization restriction, such as $\boldsymbol{\beta}_{J}=\mathbf{0}$, is required.

To impute the age, we estimated the model represented by equation 4 using the observations of the 2010 survey for each five-year age class. In other words, we estimated the model 10 times, one for each subset (corresponding to one of the age classes) of the 2010 survey. The $Y_{i}$ variable is the age of the reference person. The possible values are the ages in the corresponding age class (e.g., in the case of the [25;29] age class these are the values $25,26,27$, 28 and 29). We used the resulting estimates of the $\boldsymbol{\beta}_{j}$ 's to impute the ages of the reference persons in the 2000 and 2015 surveys. For the 2005 survey we had to estimate the model for each subset of the 2010 data corresponding to one of the age classes reported in the 2005 survey: [25;29], [30;44], [45;64] and $[65 ; 74]$. The explanatory variables $\left(\mathbf{x}_{i}\right)$ were the same in all cases and their choice was limited by the data available in IDEF: the gender of the reference person, whether the reference person has a partner, the number of ancestors in the household, the number of descendents in the household, the level of education of the reference person, the NUTS 2 region where the household resides, the work status of the reference person and the share of each category of expenditure in total expenditure.

The age imputed to each household was the age to which the model assigned the highest probability. Does our result on the flatness of the lifecycle consumption profile depend on this choice? To answer this question we constructed 500 alternative age samples. Each age sample was obtained by randomly drawing an age for each individual from the distribution implied for that individual by the estimated model. We re-estimated the consumption profile using each of these 500 age samples instead of the maximumprobability age. Then, for each of the newly estimated 500 consumption profiles, we computed the percent difference between maximum total expenditure across the life cycle and total expenditure at age 25. Table A.2 
Table A.2: Distribution of the maximum increase in total expenditure

\begin{tabular}{ccc}
\hline \hline maximum percent increase & frequency $(\%)$ & accumulated frequency \\
\hline$[2 ; 4[$ & 1.4 & 1.4 \\
{$[4 ; 6[$} & 4.6 & 6.0 \\
{$[6 ; 8[$} & 9.0 & 15.0 \\
{$[8 ; 10[$} & 21.2 & 36.2 \\
{$[10 ; 12[$} & 22.4 & 58.6 \\
{$[12 ; 14[$} & 22.4 & 81.0 \\
{$[14 ; 16[$} & 13.2 & 94.2 \\
{$[16 ; 18[$} & 4.8 & 99.0 \\
{$[18 ; 20[$} & 1.0 & 100.0 \\
\hline \hline
\end{tabular}

presents the results. The maximum relative variation was always under $20 \%$. It was below $14 \%$ for $81 \%$ of the simulated age samples. Using the maximumprobability age, in section 4.1 we reported this change to be $13 \%$. Therefore, our conclusion regarding the flatness of the consumption profile appears to be robust to the imputed age. 